Review Article

\title{
The Protective Effect of Transcription Factor 7-Like 2 Risk Allele rs7903146 against Elevated Fasting Plasma Triglyceride in Type 2 Diabetes: A Meta-Analysis
}

\author{
Shuxia Wang, ${ }^{1,2}$ Kangxing Song, ${ }^{1,3}$ Roshni Srivastava, ${ }^{2}$ Mohsen Fathzadeh, ${ }^{2}$ \\ $\mathrm{Na} \mathrm{Li}{ }^{2}$ and Arya Mani ${ }^{2,4}$ \\ ${ }^{1}$ The Geriatric Cardiology Department, Chinese PLA General Hospital, Beijing 100853, China \\ ${ }^{2}$ Yale Cardiovascular Research Center, Department of Internal Medicine, Yale University School of Medicine, \\ New Haven, CT 06511, USA \\ ${ }^{3}$ Department of Cardiology, Chinese PLA General Hospital, No. 28, Fuxing Road, Beijing 100853, China \\ ${ }^{4}$ Department of Genetics, Yale University School of Medicine, New Haven, CT 06520, USA
}

Correspondence should be addressed to Arya Mani; arya.mani@yale.edu

Received 14 January 2015; Revised 17 March 2015; Accepted 28 March 2015

Academic Editor: Thomas Pulinilkunnil

Copyright (C) 2015 Shuxia Wang et al. This is an open access article distributed under the Creative Commons Attribution License, which permits unrestricted use, distribution, and reproduction in any medium, provided the original work is properly cited.

\begin{abstract}
Background. The results from published studies regarding association of transcription factor 7-like 2 (TCF7L2) variant rs7903146 with dyslipidemia have been conflicting and inconclusive. Methods. We carried out a meta-analysis that aimed to investigate the association of the rs7903146 variant with plasma lipid levels using electronic database and published studies. Data was extracted by a standard algorithm. Dominant, recessive, homozygote, and heterozygote comparison models were utilized. Results. 24 studies incorporating 52,785 subjects were included in this meta-analysis. Overall, the minor allele $(\mathrm{T})$ was associated with lower risk for hypertriglyceridemia in subjects with type 2 diabetes (dominant model: $\mathrm{SMD}=-0.04,95 \% \mathrm{CI}(-0.08,0.00), P=0.048, P_{\text {heterogeneity }}=$ 0.47 ; recessive model: $\left.\mathrm{SMD}=-0.10,95 \% \mathrm{CI}(-0.18,-0.02), P=0.01, P_{\text {heterogeneity }}=0.56\right)$. No association was found between minor (T) allele and plasma TC, LDL-c, or HDL-c levels in subjects with type 2 diabetes or metabolic syndrome (MetS) and no association was found between minor (T) allele and plasma TG levels in nondiabetic subjects. Conclusions. Our meta-analysis indicated the association between TCF7L2 rs7903146 polymorphism and low plasma triglyceride (TG) level in subjects with type 2 diabetes. No association was found between rs7903146 variant and plasma lipids in nondiabetic subjects.
\end{abstract}

\section{Introduction}

Dyslipidemia is a major risk factor for coronary heart disease and stroke $[1,2]$. Despite extensive investigations, the underlying molecular mechanism of the disease in the general population is not understood [1]. Dyslipidemia is an inherited disorder with an estimated heritability of up to $60 \%$ for total cholesterol (TC) and HDL cholesterol (HDL-c) and $80 \%$ for plasma TG $[2,3]$. With few exceptions, it is a complex trait caused by multiple genetic variations that together exert a sizeable effect on the trait [3].

The transcription factor 7-like 2 gene (TCF7L2), a Wnt signaling pathway effector, has been shown to be involved in the differentiation of adipocytes, regulation of adipokines, and pancreatic beta-cell function [4]. Polymorphisms of TCF7L2 have been identified as one of the most important genetic predictors of type 2 diabetes in genome-wide association studies [5]. The minor allele (T) of the TCF7L2 rs7903146 variant $(\mathrm{C} / \mathrm{T})$, located in intron 4 of TCF7L2, has been associated with increased risk for type 2 diabetes $[6,7]$. In addition, several studies have suggested association between TCF7L2 rs7903146 polymorphism and dyslipidemia, but the results have been conflicting [8-11]. The objective of our meta-analysis was to investigate the association of the polymorphism rs7903146 of TCF7L2 with plasma lipids. 


\section{Methods}

2.1. Literature Search. We systematically searched PubMed, Cochrane Library, Embase, reviews, and reference lists of relevant manuscripts before February 2014 by using Medical Subject Heading (MeSH) terms "Transcription Factor 7-like 2" or "TCF7L2" or "TCF7L" alone or paired with the following terms: "polymorphism," "variant," "SNP," or "mutation." The following four plasma lipids were included in our metaanalysis: TC, TG, LDL-c, and HDL-c.

2.2. Study Selection Criteria. The selection criteria for eligible studies were the following: (1) studies had to include data reported on at least one of the four fasting plasma lipids; (2) mean plasma lipid levels and standard deviations (SD) or standard errors were available; (3) studies included genotyping data; (4) study subjects were 18 years of age or older; (5) baseline data before intervention were available for interventional studies. Animal studies, case reports, review articles, abstracts, reports with incomplete data, and familybased studies were excluded.

2.3. Quality Assessment. The Newcastle-Ottawa Scale (NOS) was used to assess the quality of the studies. The NOS contains eight items categorized into three dimensions including selection, comparability, and exposure for case-control studies. In our meta-analysis, the NOS ranged from four to nine stars.

2.4. Data Extraction. Two investigators (Shuxia Wang and Kangxing Song) extracted data independently and discrepancies were resolved by consensus including a third author. Data were extracted using standardized methods. The following data were collected: article reference, first author, publication year, demographics including racial backgrounds, gender, age, health condition, and fasting status of the study subjects, mean and SD or standard error for the genotyping studies, genotyping methods, lipid assays, and unit of measurements.

2.5. Statistics and Analysis. Stata software (version 12.0, Stata Corporation, College Station, TX) and Review Manager 5.0 software (The Cochrane Collaboration, Oxford, UK) were used for the meta-analysis. Four different genetic models, including dominant model (TT + TC versus $\mathrm{CC}$ ), recessive model (TT versus TC + CC), homozygote (TT versus CC), and heterozygote comparisons (TC versus $\mathrm{CC}$ ), were used in our analysis. All data in this analysis were presented as mean $\pm \mathrm{SD}$. The SD was derived whenever the standard errors were reported. A pooled standardized mean difference (SMD) together with $95 \%$ confidence interval (CI) was used for this meta-analysis. SMD was selected to eliminate the effect of multiple scanners used for plasma lipid measurements [32]. A fixed-effect model was used for $P$ values greater than 0.10 of the $\chi^{2}$-based heterogeneity $Q$-tests, and random effect model was used for $P$ values less than 0.10 . The $I^{2}$ heterogeneity estimates were calculated and divided into 4 groups $\left(I^{2}=0-\right.$ $25 \%$, no heterogeneity; $I^{2}=25-50 \%$, moderate heterogeneity; $I^{2}=50-75 \%$, large heterogeneity; $I^{2}=75-100 \%$, extreme heterogeneity). The units of plasma lipids were converted from $\mathrm{mmol} / \mathrm{L}$ to $\mathrm{mg} / \mathrm{dL}$, whenever necessary.

Funnel plots were used to evaluate publication bias. The funnel plots are asymmetric when there is publication bias. Egger's test, using MIX 1.7 software, was performed to estimate the degree of asymmetry of funnel plots. A stringent threshold of $P<0.1$ was used as an indication for significant publication bias.

\section{Results}

3.1. Search Results. A total of 490 articles were identified searching PubMed, Embase, and Cochrane Library databases and from a manual approach (search of previous studies cited in the reviews and the reference lists of identified articles); 461 articles were excluded because they were not conducted in human or did not meet the goals of this metaanalysis. Full text assessment of the 29 potentially relevant articles resulted in 24 eligible studies that met the inclusion criteria for the meta-analysis (Figure 1). The most common reasons for the exclusions were as follows: data were limited to isolated pedigrees $[33,34]$, were incomplete [35], or involved subjects younger than 18 years of age [36] and/or belonged to subjects that were studied in 2 or more published studies [37] (Figure 1).

A total of 24 studies [8-29, 31, 37] were included in the meta-analysis. The selected study characteristics are summarized in Table 1 . There were 21, 21, 18, and 19 studies that reported plasma TC, TG, LDL-c, and HDL-c, respectively. Twenty-two studies included both men and women, one study [22] included only women, and one study [14] included only men. Within the eligible studies, eight $[10,12,13,15,19$, $26,28,31]$ involved subjects with diabetes, three $[8,21,27]$ involved subjects with MetS, twelve $[8,10,12-16,20,24$, $25,27,28$ ] involved nondiabetic healthy subjects, and eight $[9,11,17,18,22,23,29,37]$ involved general (communitybased/population-based) subjects. Overall, 52,785 subjects were enrolled in this meta-analysis.

3.2. Association between rs7903146 and Plasma TG. The analysis under a dominant model on 30 comparisons showed that the carriers of $\mathrm{T}$ allele had tendency toward lower plasma TG than the noncarriers, but the results were not statistically significant: $P=0.07, \mathrm{SMD}=-0.02$, and $95 \% \mathrm{CI}$ $(-0.04,0.00)$ (Figure $2(a))$. No significant heterogeneity for this outcome was found (heterogeneity $\chi^{2}=36.54, I^{2}=21 \%$, $P_{\text {heterogeneity }}=0.16$ ) (Figure $2(\mathrm{a})$ ). Under the recessive model, the carriers of TT genotype had significantly lower plasma TG than the noncarriers: $P=0.008, \mathrm{SMD}=-0.05$, and $95 \%$ CI $(-0.09,-0.01)$ (Figure 2(b)). The heterogeneity for this outcome was significant (heterogeneity $\chi^{2}=33.65, I^{2}=41 \%$, $P_{\text {heterogeneity }}=0.03$ ) (Figure 2(b)). Under the homozygote comparison model, the carriers of TT genotype had lower plasma TG than CC genotype: $P=0.0086, \mathrm{SMD}=-0.06$, 


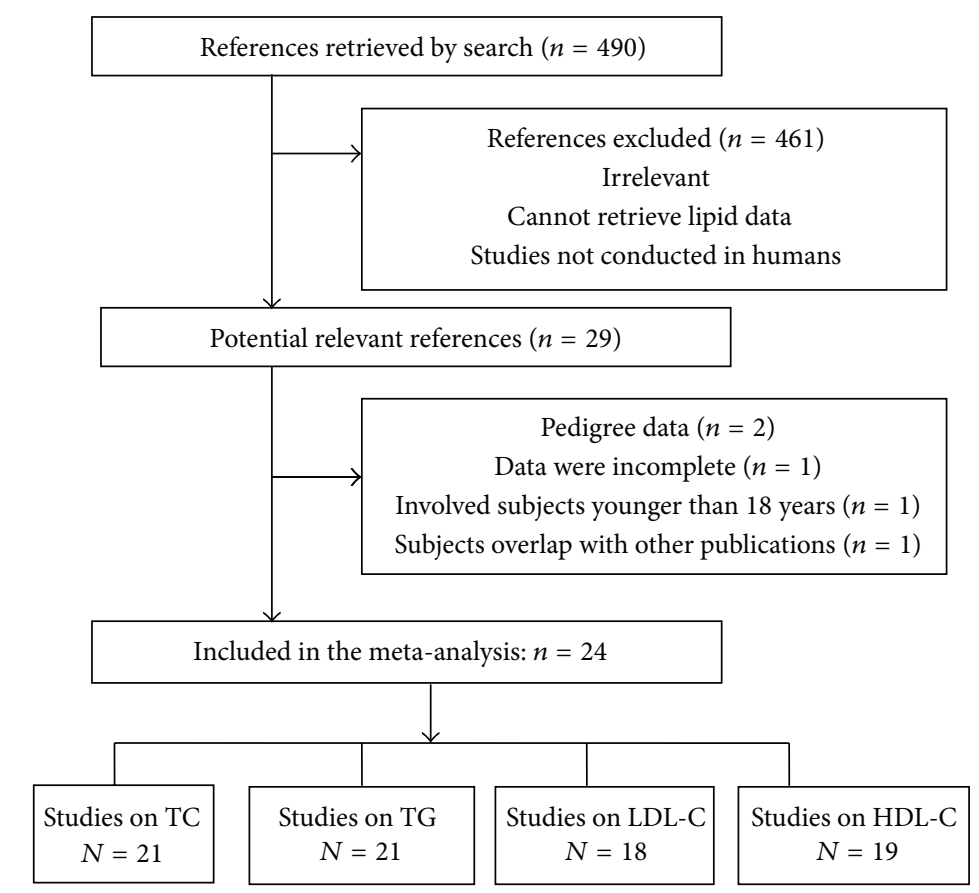

FIGURE 1: Flowchart outlining the process of search criteria and study selection.

and $95 \%$ CI $(-0.10,-0.02)$ (Figure $2(\mathrm{c}))$. The heterogeneity for this outcome was also significant (heterogeneity $\chi^{2}=$ $38.98, I^{2}=56 \%, P_{\text {heterogeneity }}=0.002$ ) (Figure $\left.2(\mathrm{c})\right)$. No difference was found in TG level between the carriers of TC genotype and CC genotype under heterozygote comparison model: $P=0.18$, SMD $=-0.02$, and 95\% CI $(-0.04,0.01)$ (Figure 2(d)). The heterogeneity for this outcome was also significant (heterogeneity $\chi^{2}=27.42, I^{2}=42 \%, P_{\text {heterogeneity }}=$ 0.02 ) (Figure 2(d)).

We then performed the subgroup analyses of the study population under four different genetic models.

Under dominant model, there was significant association between low plasma TG and T allele in diabetic subjects: $P=$ $0.048, \mathrm{SMD}=-0.04,95 \% \mathrm{CI}(-0.08,0.00), P_{\text {heterogeneity }}=0.47$, but not in metabolic syndrome (MetS) subjects: $P=0.49$, SMD $=-0.06,95 \%$ CI $(-0.21,0.10), P_{\text {heterogeneity }}=0.96$, or the nondiabetic subjects: $P=0.99, \mathrm{SMD}=0.00,95 \% \mathrm{CI}$ $(-0.04,0.04), P_{\text {heterogeneity }}=0.48$, or the general population: $P=0.27, \mathrm{SMD}=-0.02,95 \% \mathrm{CI}(-0.05,0.01), P_{\text {heterogeneity }}=$ 0.02 (Figure 2(a)).

Under a recessive model, there was significant association between low plasma TG and TT genotype in diabetic subjects: $P=0.01, \mathrm{SMD}=-0.10,95 \% \mathrm{CI}(-0.18,-0.02), P_{\text {heterogeneity }}=$ 0.56 (Figure 2(b)), but not in nondiabetic subjects: $P=0.56$, SMD $=-0.03,95 \%$ CI $(-0.13,0.07), P_{\text {heterogeneity }}=0.66$, or the general population: $P=0.15, \mathrm{SMD}=-0.04,95 \% \mathrm{CI}(-0.09$, $0.01), P_{\text {heterogeneity }}=0.001$ (Figure 2(b)).

Under a homozygote comparison model, there was no significant association between low plasma TG and TT versus CC genotype in any of the subgroups: diabetic subjects $(P=$ $\left.0.22, \mathrm{SMD}=-0.13,95 \% \mathrm{CI}(-0.33,0.08), P_{\text {heterogeneity }}=0.19\right)$,
MetS subjects $(P=0.62, \mathrm{SMD}=-0.08,95 \% \mathrm{CI}(-0.39,0.23)$, $\left.P_{\text {heterogeneity }}=0.54\right)$, nondiabetic subjects $(P=0.32, \mathrm{SMD}=$ $-0.04,95 \%$ CI $\left.(-0.12,0.04), P_{\text {heterogeneity }}=0.77\right)$, or general population $(P=0.19, \mathrm{SMD}=-0.13,95 \% \mathrm{CI}(-0.33,0.16)$, $P_{\text {heterogeneity }}<0.00001$ ) (Figure 2(c)).

Under a heterozygote comparison model, there was no significant association between low plasma TG and TT/TC versus CC genotype in any of the subgroups: diabetic subjects $\left(P=0.25, \mathrm{SMD}=-0.05,95 \% \mathrm{CI}(-0.12,0.03), P_{\text {heterogeneity }}=\right.$ $0.01)$ or MetS subjects $(P=0.48, \mathrm{SMD}=-0.06,95 \% \mathrm{CI}$ $\left.(-0.25,0.12), P_{\text {heterogeneity }}=0.76\right)$, nondiabetic subjects $(P=$ $\left.0.68, \mathrm{SMD}=-0.01,95 \% \mathrm{CI}(-0.08,0.05), P_{\text {heterogeneity }}=0.94\right)$, and general population $(P=0.99, \mathrm{SMD}=0.00,95 \% \mathrm{CI}$ $\left.(-0.08,0.09), P_{\text {heterogeneity }}=0.02\right)($ Figure $2(\mathrm{~d}))$.

\subsection{Association between TCF7L2 rs7903146 Polymorphism} and $T C, H D L-c$, and $L D L-c$. We performed the metaanalysis of the association of TCF7L2 rs7903146 polymorphism with TC, HDL-c, and LDL-c. There were no differences between rs7903146 polymorphism with TC, HDL$c$, and LDL-c under 4 different genetic models (dominant, recessive, homozygote, and heterozygote) (Supplement Figures 1-3 in Supplementary Material available online at http://dx.doi.org/10.1155/2015/468627).

We then divided the study population into diabetic subjects, MetS subjects, nondiabetic subjects, and general populations using four different genetic models. No associations between rs7903146 polymorphism and TC, HDL-c, and LDL-c were detected in any of the subgroups under any of the four models (Supplement Figures 1-3). 
TABLE 1: Characteristics of the study populations in the included studies.

\begin{tabular}{|c|c|c|c|c|c|}
\hline $\begin{array}{l}\text { First author, year, and } \\
\text { reference }\end{array}$ & Ethnicity & Gender & Age & Study population & Outcome \\
\hline Sousa 2009 [10] & Brazil & $\mathrm{M} / \mathrm{F}$ & $58.4-62.7$ & $\begin{array}{l}\text { Nondiabetic subjects, } \\
\text { diabetic subject }\end{array}$ & $\begin{array}{c}\text { TC, LDL-c, HDL-c, } \\
\text { TG }\end{array}$ \\
\hline Muendlein 2011 [12] & Austria & $\mathrm{M} / \mathrm{F}$ & $63.3-65.9$ & $\begin{array}{l}\text { Diabetic subject, } \\
\text { nondiabetic subjects }\end{array}$ & $\begin{array}{c}\text { TC, LDL-c, HDL-c, } \\
\text { TG }\end{array}$ \\
\hline Palizban 2012 [13] & Iran & $\mathrm{M} / \mathrm{F}$ & $50.4-59.3$ & $\begin{array}{l}\text { Diabetic subject, } \\
\text { nondiabetic subjects }\end{array}$ & TC, TG \\
\hline Then 2013 [14] & German & M & $51-58$ & Nondiabetic subjects & $\begin{array}{c}\text { TC, LDL-c, HDL-c, } \\
\text { TG }\end{array}$ \\
\hline Kahveci 2012 [15] & Turkey & $\mathrm{M} / \mathrm{F}$ & $36-84$ & $\begin{array}{l}\text { Diabetic subject and } \\
\text { nondiabetic subjects }\end{array}$ & $\begin{array}{c}\text { TC, LDL-c, HDL-c, } \\
\text { TG }\end{array}$ \\
\hline Bodhini 2007 [16] & Asian Indians & $\mathrm{M} / \mathrm{F}$ & $41 \pm 11$ & $\begin{array}{l}\text { Normal glucose } \\
\text { tolerant subjects }\end{array}$ & $\begin{array}{c}\text { TC, LDL-c, HDL-c, } \\
\text { TG }\end{array}$ \\
\hline $\begin{array}{l}\text { Warodomwichit } 2009 \\
\text { [9] }\end{array}$ & $\begin{array}{l}\text { European } \\
\text { Americans }\end{array}$ & $\mathrm{M} / \mathrm{F}$ & $17-92$ ys & $\begin{array}{l}\text { The Genetics of Lipid } \\
\text { Lowering Drugs and } \\
\text { Diet Network } \\
\text { (GOLDN) study }\end{array}$ & $\begin{array}{c}\text { TC, LDL-c, HDL-c, } \\
\text { TG }\end{array}$ \\
\hline Melzer 2006 [11] & $\begin{array}{l}\text { White European } \\
\text { origin }\end{array}$ & $\mathrm{M} / \mathrm{F}$ & $\geq 65$ ys & $\begin{array}{l}\text { Older population } \\
\text { from InCHIATI study }\end{array}$ & $\begin{array}{c}\text { TC, LDL-c, HDL-c, } \\
\text { TG }\end{array}$ \\
\hline Marquezine 2008 [17] & Brazil & $\mathrm{M} / \mathrm{F}$ & $44.3-59.8$ & $\begin{array}{l}\text { Multivessel coronary } \\
\text { artery disease } \\
\text { patients, general } \\
\text { population }\end{array}$ & TC, HDL-c, TG \\
\hline Musso 2009 [18] & Italy & $\mathrm{M} / \mathrm{F}$ & $38-41$ & $\begin{array}{l}\text { Healthy control, } \\
\text { nonalcoholic fatty } \\
\text { liver disease }\end{array}$ & $\begin{array}{c}\text { TC, LDL-c, HDL-c, } \\
\text { TG }\end{array}$ \\
\hline Choi 2014 [19] & Korea & $\mathrm{M} / \mathrm{F}$ & $59-60$ & Diabetic patients & $\begin{array}{c}\text { TC, LDL-c, HDL-c, } \\
\text { TG }\end{array}$ \\
\hline Wang 2013 [20] & Chinese & $\mathrm{M} / \mathrm{F}$ & $20-85$ & Nondiabetic controls & $\begin{array}{c}\text { TC, LDL-c, HDL-c, } \\
\text { TG }\end{array}$ \\
\hline $\begin{array}{l}\text { Delgado-Lista } 2011 \\
\text { [21] }\end{array}$ & $\begin{array}{l}\text { LIPGENE dietary } \\
\text { intervention from } 8 \\
\text { European countries }\end{array}$ & $\mathrm{M} / \mathrm{F}$ & $35-70$ ys & $\begin{array}{l}\text { Metabolic syndrome } \\
\text { according to NCEP } \\
\text { criteria }\end{array}$ & $\begin{array}{c}\text { TC, LDL-c, HDL-c, } \\
\text { TG }\end{array}$ \\
\hline $\begin{array}{l}\text { Perez-Martinez } 2012 \\
\text { [8] }\end{array}$ & Ireland & $\mathrm{M} / \mathrm{F}$ & $22-68.4$ & $\begin{array}{l}\text { Young men, } \\
\text { metabolic syndrome, } \\
\text { and healthy elderly }\end{array}$ & $\begin{array}{c}\text { TC, LDL-c, HDL-c, } \\
\text { TG }\end{array}$ \\
\hline Ramos 2013 [22] & Brazil & $\mathrm{F}$ & $22.8 \pm 6.6$ & $\begin{array}{l}\text { Women with } \\
\text { polycystic ovary } \\
\text { syndrome }\end{array}$ & $\begin{array}{c}\text { TC, LDL-c, HDL-c, } \\
\text { TG }\end{array}$ \\
\hline Gambino 2010 [23] & Caucasian, Italy & $\mathrm{M} / \mathrm{F}$ & $54.2-54.7$ & $\begin{array}{c}\text { Population-based } \\
\text { cohort }\end{array}$ & LDL-c, HDL-c \\
\hline Cauchi 2007 [24] & Caucasian, French & $\mathrm{M} / \mathrm{F}$ & Around 22 & $\begin{array}{l}\text { Small gestational age, } \\
\text { appropriate for } \\
\text { gestational age birth } \\
\text { weight }\end{array}$ & TC, TG \\
\hline Cauchi 2006 [25] & French & $\mathrm{M} / \mathrm{F}$ & $30-65$ & Normoglycemic & $\begin{array}{c}\text { TC, LDL-c, HDL-c, } \\
\text { TG }\end{array}$ \\
\hline Humphries 2006 [26] & $\begin{array}{l}\text { European White, } \\
\text { Indian Asia, } \\
\text { Afro-Caribbean }\end{array}$ & $\mathrm{M} / \mathrm{F}$ & $62.4-63$ & $\begin{array}{l}\text { Diabetic patients, } \\
\text { healthy subjects }\end{array}$ & $\begin{array}{c}\text { TC, LDL-c, HDL-c, } \\
\text { TG }\end{array}$ \\
\hline Bo 2009 [27] & Italy & $\mathrm{M} / \mathrm{F}$ & $55.2-56.8$ & $\begin{array}{c}\text { Nondiabetic } \\
\text { dysmetabolic } \\
\text { participants, control }\end{array}$ & HDL-c, TG \\
\hline
\end{tabular}


TABle 1: Continued.

\begin{tabular}{|c|c|c|c|c|c|}
\hline $\begin{array}{l}\text { First author, year, and } \\
\text { reference }\end{array}$ & Ethnicity & Gender & Age & Study population & Outcome \\
\hline Ereqat 2010 [28] & Palestinian & $\mathrm{M} / \mathrm{F}$ & $>40 \mathrm{ys}$ & $\begin{array}{c}\text { Diabetic subject, } \\
\text { nondiabetic subjects }\end{array}$ & TC \\
\hline Yan 2009 [29] & $\begin{array}{c}\text { African American, } \\
\text { Caucasian }\end{array}$ & $\mathrm{M} / \mathrm{F}$ & $53-54$ & $\begin{array}{c}\text { The Atherosclerosis } \\
\text { Risk in Communities } \\
\text { Study (ARIC) }\end{array}$ & LDL-c, HDL-c, TG \\
\hline Yan 2010 [30] & $\begin{array}{c}\text { African American, } \\
\text { Caucasian }\end{array}$ & $\mathrm{M} / \mathrm{F}$ & $58.3-60.1$ & $\begin{array}{c}\text { The Atherosclerosis } \\
\text { Risk in Communities } \\
\text { Study (ARIC) }\end{array}$ & TC \\
\hline Schroner 2011 [31] & Slovakia & $\mathrm{M} / \mathrm{F}$ & $62.6-63.1$ & $\begin{array}{c}\text { Diabetic subject with } \\
\text { HbA1C }<7.0 \%\end{array}$ & $\begin{array}{c}\text { TC, LDL-c, HDL-c, } \\
\text { TG }\end{array}$ \\
\hline
\end{tabular}

3.4. Publication Bias. Publication bias was assayed by visual funnel plot inspection and Egger's test. The funnel plots comparing the differences in TC, TG, LDL-c, and HDL-c were all symmetric (Figures 3(a)-3(d) and Supplement Figures 4$6 \mathrm{~A}-\mathrm{D}$, resp.) and Egger's test did not indicate asymmetry of the plots.

\section{Discussion}

Our meta-analysis suggests that in subjects with type 2 diabetes or metabolic syndrome the minor TCF7L2 allele (rs7903146) has a protective effect against plasma TG but not TC, LDL-c, and HDL-c levels. There was no association between the minor allele and plasma lipids in nondiabetic subjects.

TCF7L2 rs7903146 is the most common susceptibility variant for type 2 diabetes across the world $[6,7]$. The variant is associated with increased mRNA expression of TCF7L2 in pancreas $[38,39]$. It increases the risk of type 2 diabetes by modifying the effect of incretins on insulin secretion [40], increasing gluconeogenesis and insulin resistance [41]. Accordingly, conditional deletion of TCF7L2 in adult hepatocytes results in reduced hepatic gluconeogenesis and lower plasma glucose levels [39]. Correspondingly, transient hepatic overexpression of TCF7L2 results in elevated plasma glucose levels [41]. Decreased insulin secretion and action are frequently associated with the simultaneous occurrence of hyperglycemia and dyslipidemia [42]. Therefore, at first sight, the result of our meta-analysis may appear as unexpected.

These results are, however, consistent with earlier findings in animal models. These studies have suggested that TCF7L2 may regulate plasma lipids through insulin-independent pathways. We have shown in LRP6 mutant mice that impaired Wnt signaling is associated with reduced TCF7L2 expression, increased de novo lipogenesis, and cholesterol synthesis and secretion in the liver, leading to high plasma TG levels. Reduced Wnt/TCF7L2 activity in these mice results in IGF1-dependent but insulin-independent activation of AKTmTOR-SREBP axis [43]. Thus, increased TCF7L2 expression may have opposing effects on plasma glucose and plasma lipids. Alternatively, the protective effect of TCF7L2 minor variant against hypertriglyceridemia may be due to reduced adipose tissue lipolysis. In one earlier study, it was shown that reduced TCF7L2 in adipose tissue is associated with elevated triglyceride [34]. Finally, the minor allele in TCF7L2 may be in disequilibrium with other causal alleles in this gene. Regardless, these findings implicate TCF7L2 in regulation of plasma triglyceride in the general population and in conjunction with the animal studies identify this protein as a target for drugs against hyperlipidemia.

Heterogeneity was observed in some subgroups using certain models. In subgroup analysis for the association between risk allele and TG, heterogeneity was found in diabetic subjects under heterozygote model and in general subjects under all four different genetic models. For the analysis of association between LDL and the risk allele, the heterogeneity was only found under dominant model in subjects with type 2 diabetes and MetS subjects. The association analysis of HDL with risk allele showed heterogeneity for subjects with type 2 diabetes and general subjects under dominant, recessive, and heterozygote models. There was no heterogeneity in subgroup analysis of TC with risk allele. Random effect models were used to decrease the effect of heterogeneity in subgroup analysis. The present analysis had several limitations. First, most of the included studies were designed to study the association of TCF7L2 variants with diabetes $[11,13,15-17,19,20,26,28,29,31]$, hyperglycemia [23, $25]$, and coronary artery disease [10] and only 2 studies $[8,9]$ were exclusively designed to examine the association between rs7903146 and plasma lipid levels. For all other studies, the lipid levels had to be extracted from baseline characteristics of the study populations. These studies were not designed to introduce the necessary adjustments for confounding factors such as lifestyle changes and medications [27]. Nonetheless, the effects of such variables were significantly reduced in our analysis by using preintervention baseline data. Second, the meta-analysis was based on unadjusted estimates. In absence of detailed demographics, a post hoc analysis of adjusted estimates could not be carried out. One other limitation is related to inadequate data on MetS. There were only two publications that specifically studied subjects with MetS. Consequently, no analyses could be carried out for this subgroup. 


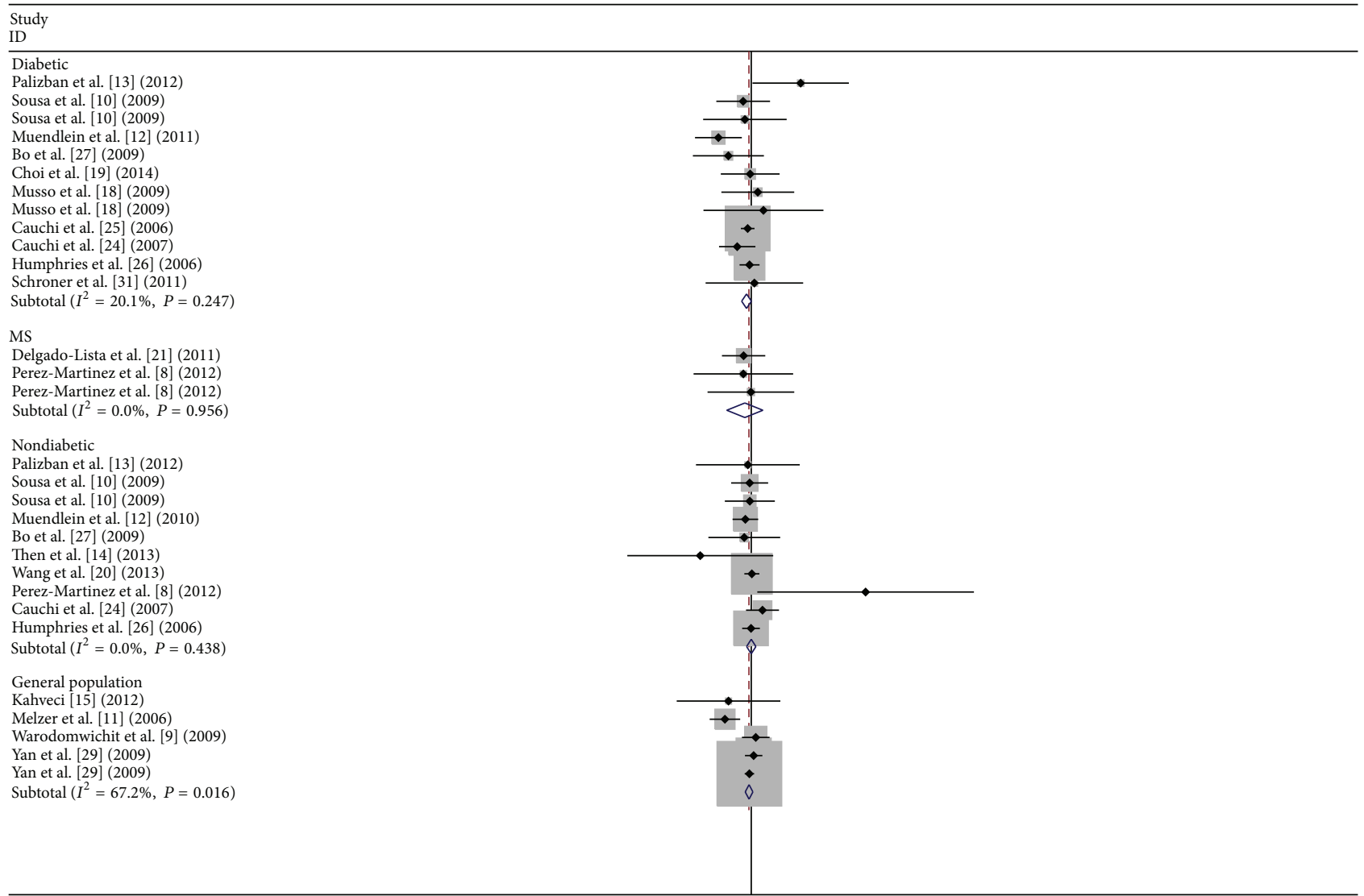

(a)

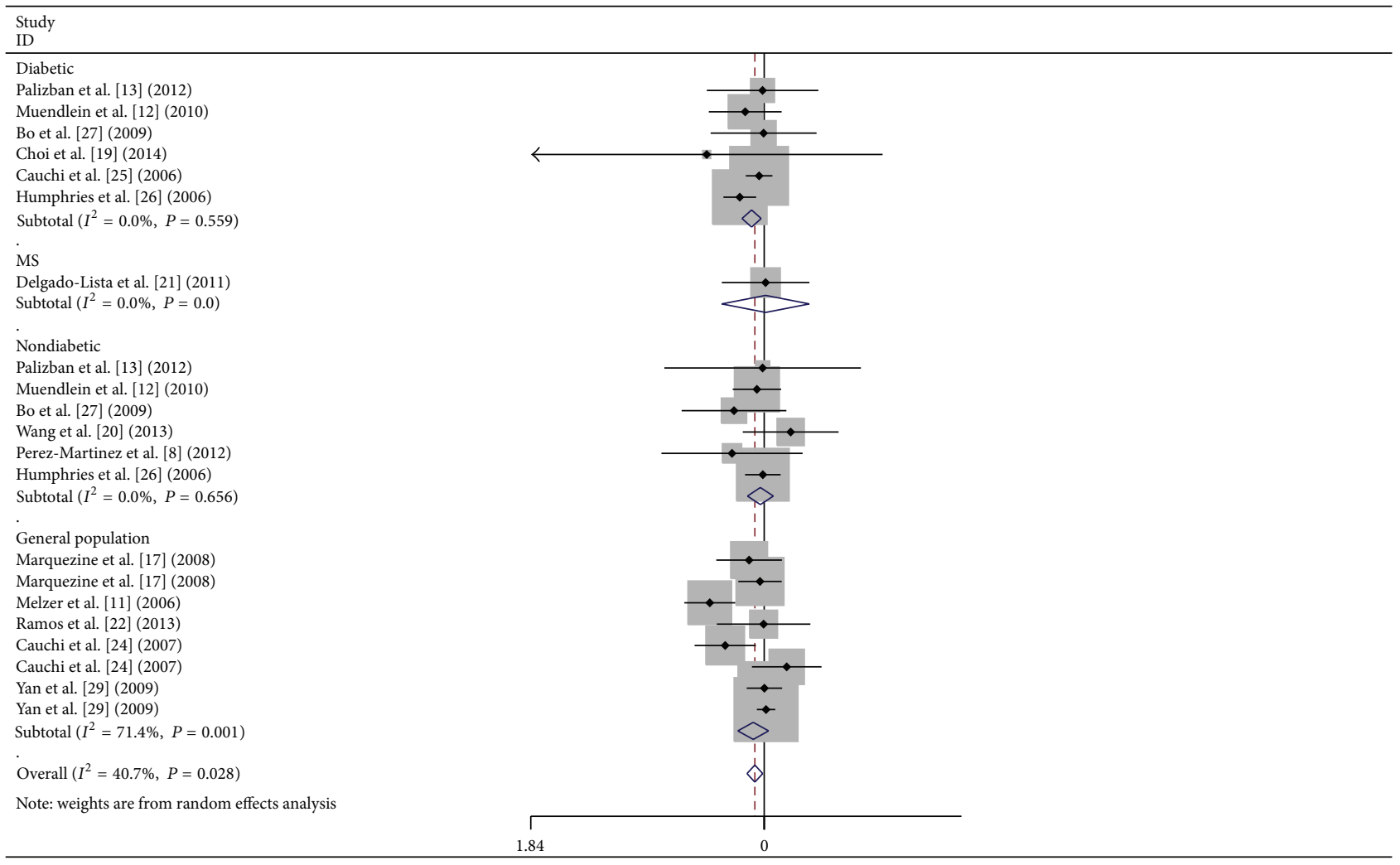

(b)

Figure 2: Continued. 


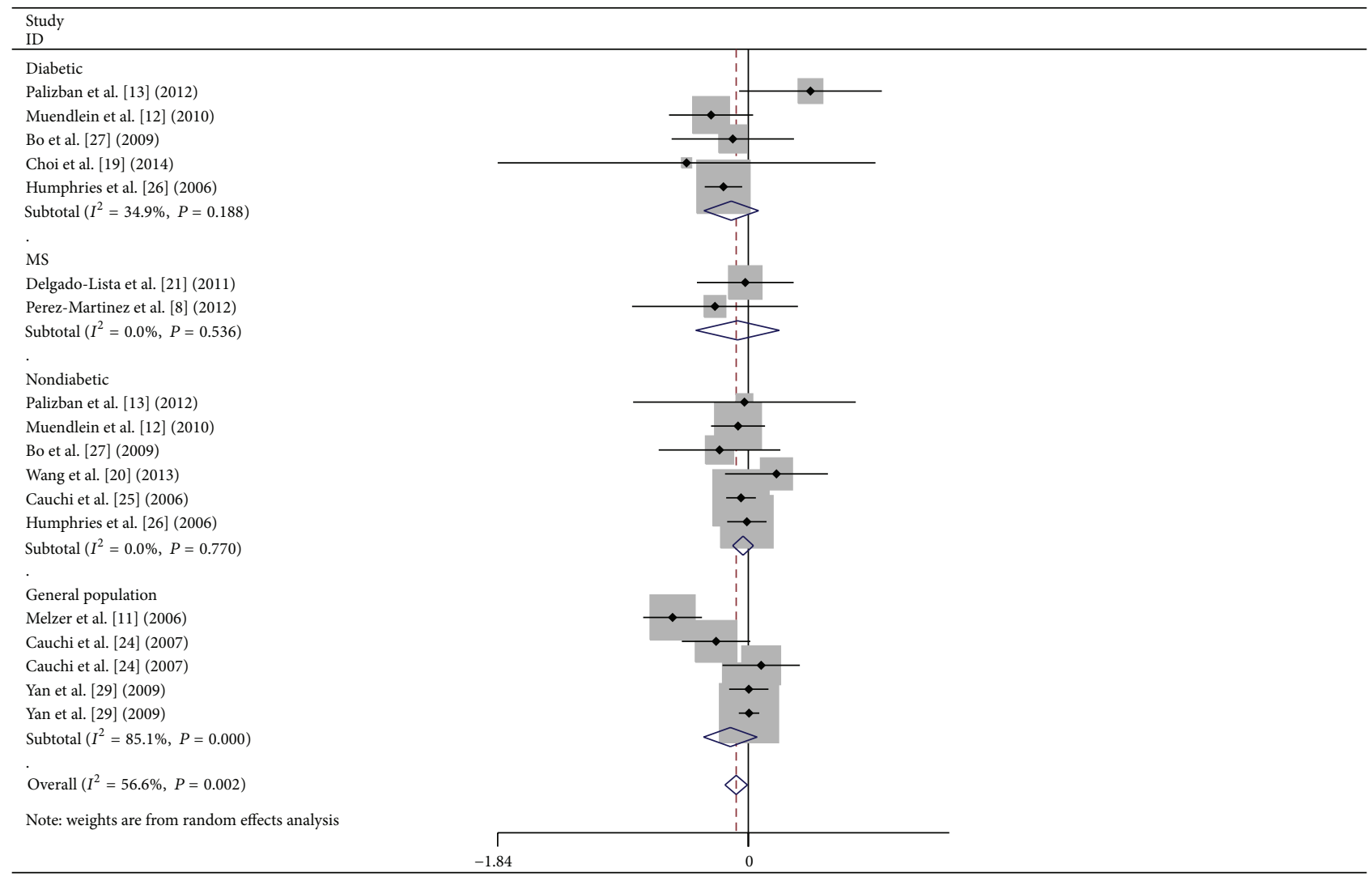

(c)

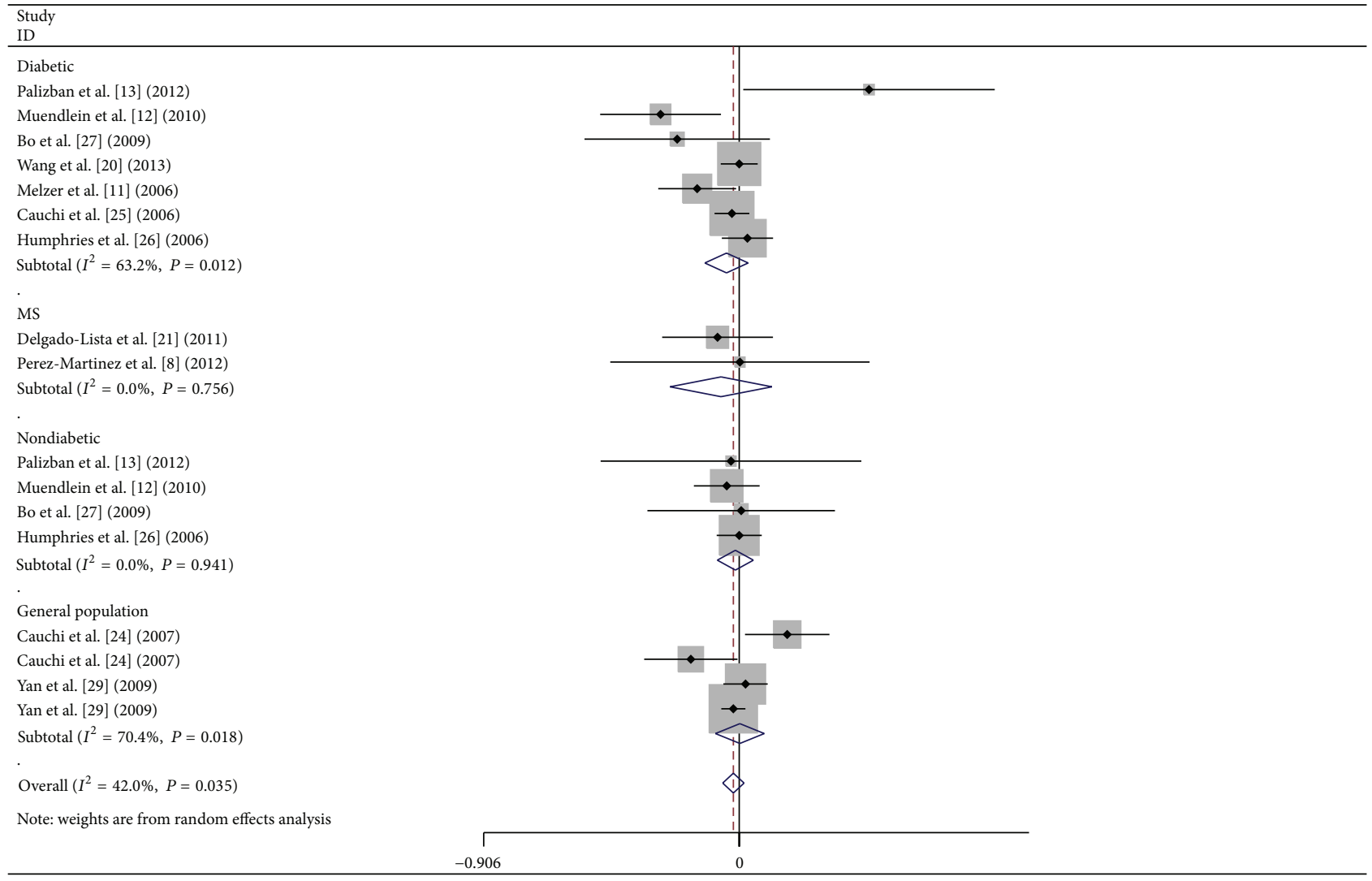

(d)

Figure 2: Forest plot of the TGCF7L2 rs7903146 polymorphism and triglyceride association: (a) dominant model, TT + TC versus CC, (b) recessive model, TT versus TC + CC, (c) homozygous model, TT versus CC, and (d) heterozygous model, TC versus CC. 
Begg's funnel plot with pseudo 95\% confidence limits

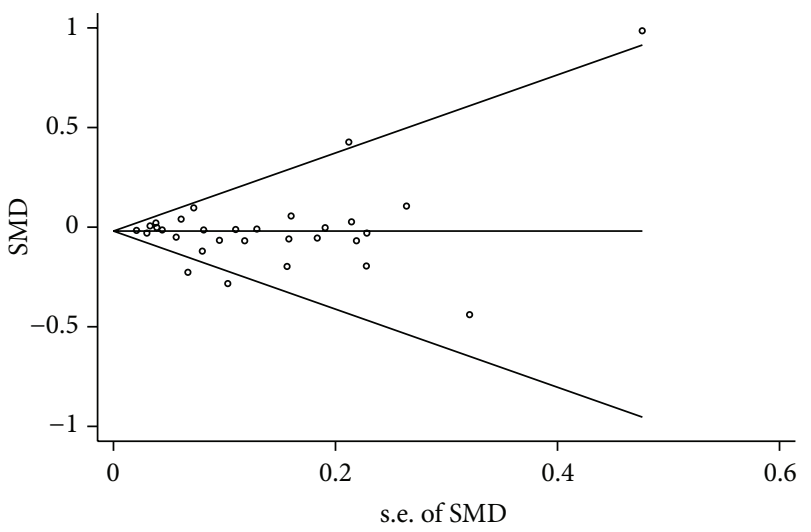

(a)

Begg's funnel plot with pseudo 95\% confidence limits

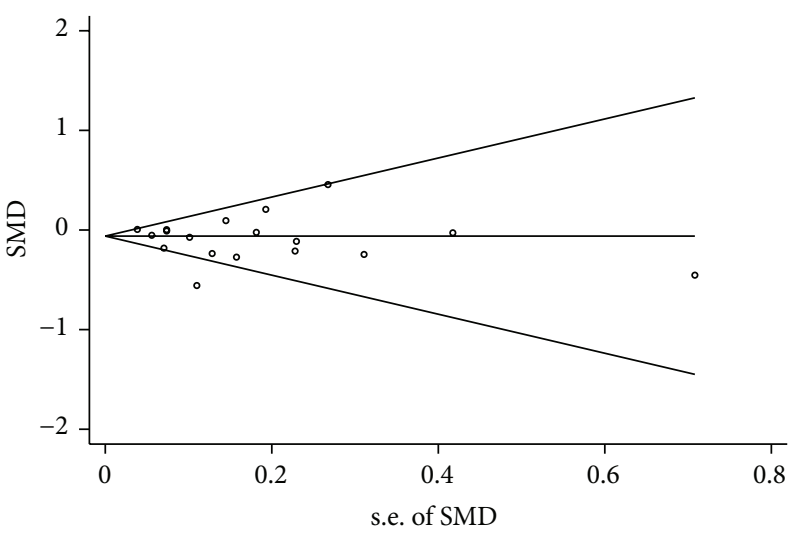

(c)

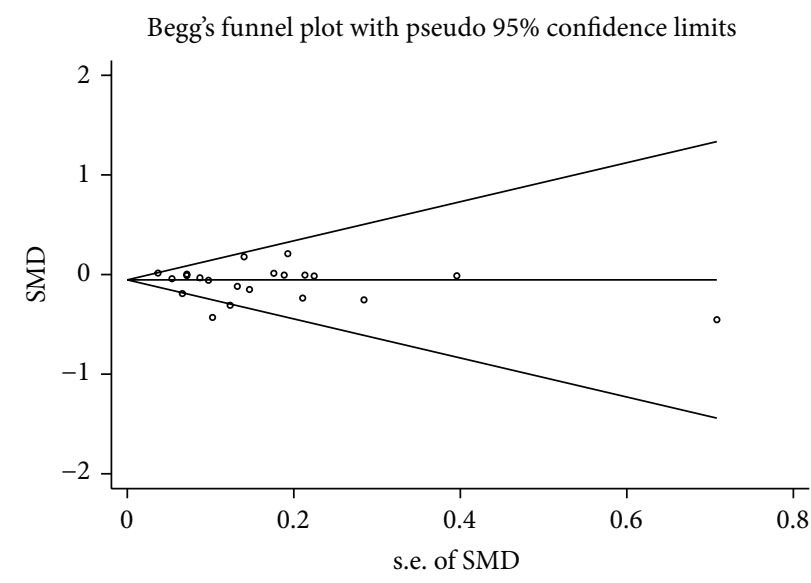

(b)

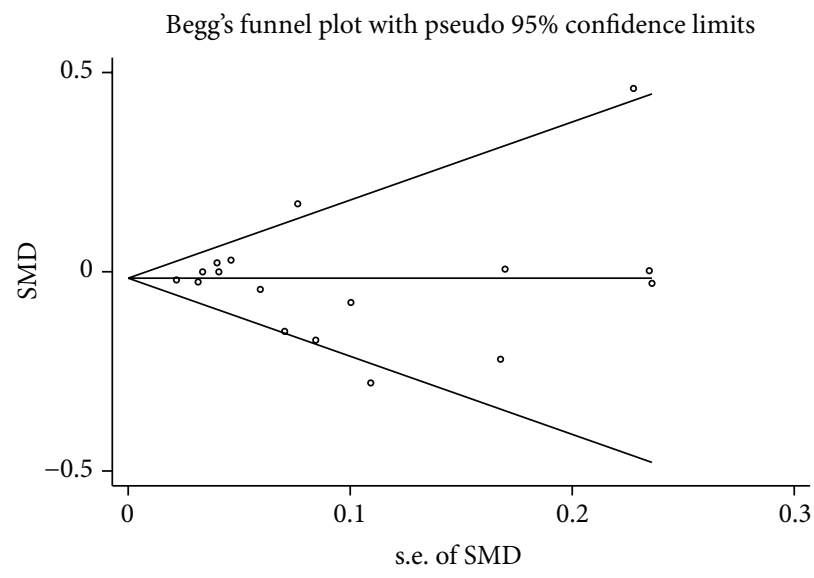

(d)

FIGURE 3: Funnel plot of TGCF7L2 rs7903146 polymorphism and triglyceride association in dominant model (a), recessive model (b), homozygous recessive model (c), and heterozygous model (d).

In conclusion, our meta-analysis identified an association between T genotype of TCF7L2 rs7903146 with lower TG level in subjects with diabetes. This finding identifies TCF7L2 as a potential target for development of novel therapeutics against hyperlipidemia.

\section{Conflict of Interests}

The authors declare that there is no conflict of interests regarding the publication of this paper.

\section{Authors' Contribution}

Shuxia Wang, Kangxing Song, and Roshni Srivastava contributed equally.

\section{Acknowledgments}

This study was supported by the American Diabetes Association Grant 1-14-BS-138 (to Arya Mani) and National Natural Science Foundation of China (Grants no. 81470504, no.
81100160) and Support Fund of PLA General Hospital of China (2013FC-CXYY-1001, 2013FC-CXYY-1003).

\section{References}

[1] A. Garg and V. Simha, "Update on dyslipidemia," The Journal of Clinical Endocrinology \& Metabolism, vol. 92, no. 5, pp. 15811589, 2007.

[2] A. J. Lusis, R. Mar, and P. Pajukanta, "Genetics of atherosclerosis," Annual Review of Genomics and Human Genetics, vol. 5, pp. 189-218, 2004.

[3] R. L. Pollex and R. A. Hegele, "Genomic copy number variation and its potential role in lipoprotein and metabolic phenotypes," Current Opinion in Lipidology, vol. 18, no. 2, pp. 174-180, 2007.

[4] S. Schinner, "Wnt-signalling and the metabolic syndrome," Hormone and Metabolic Research, vol. 41, no. 2, pp. 159-163, 2009.

[5] S. F. A. Grant, G. Thorleifsson, I. Reynisdottir et al., "Variant of transcription factor 7-like 2 (TCF7L2) gene confers risk of type 2 diabetes," Nature Genetics, vol. 38, no. 3, pp. 320-323, 2006.

[6] H. Dou, E. Ma, L. Yin, Y. Jin, and H. Wang, "The association between gene polymorphism of TCF7L2 and type 2 diabetes in 
chinese han population: a meta-analysis," PLoS ONE, vol. 8, no. 3, Article ID e59495, 2013.

[7] S. Peng, Y. Zhu, B. Lü, F. Xu, X. Li, and M. Lai, "TCF7L2 gene polymorphisms and type 2 diabetes risk: a comprehensive and updated meta-analysis involving 121,174 subjects," Mutagenesis, vol. 28, no. 1, pp. 25-37, 2013.

[8] P. Perez-Martinez, A. I. Perez-Caballero, A. Garcia-Rios et al., "Effects of rs7903146 variation in the Tcf7l2 gene in the lipid metabolism of three different populations," PLOS ONE, vol. 7, no. 8, Article ID e43390, 2012.

[9] D. Warodomwichit, D. K. Arnett, E. K. Kabagambe et al., "Polyunsaturated fatty acids modulate the effect of TCF7L2 gene variants on postprandial lipemia," The Journal of Nutrition, vol. 139, no. 3, pp. 439-446, 2009.

[10] A. G. P. Sousa, G. F. Marquezine, P. A. Lemos et al., “TCF7L2 polymorphism rs7903146 is associated with coronary artery disease severity and mortality," PLoS ONE, vol. 4, no. 11, Article ID e7697, 2009.

[11] D. Melzer, A. Murray, A. J. Hurst et al., "Effects of the diabetes linked TCF7L2 polymorphism in a representative older population," BMC Medicine, vol. 4, article 34, 2006.

[12] A. Muendlein, C. H. Saely, S. Geller-Rhomberg et al., "Single nucleotide polymorphisms of TCF7L2 are linked to diabetic coronary atherosclerosis," PLoS ONE, vol. 6, no. 3, Article ID e17978, 2011.

[13] A. Palizban, M. Nikpour, R. Salehi, and M.-R. Maracy, "Association of a common variant in TCF7L2 gene with type 2 diabetes mellitus in a Persian population," Clinical and Experimental Medicine, vol. 12, no. 2, pp. 115-119, 2012.

[14] C. Then, S. Wahl, A. Kirchhofer et al., "Plasma metabolomics reveal alterations of sphingo- and glycerophospholipid levels in non-diabetic carriers of the transcription factor 7-like 2 polymorphism rs7903146," PLoS ONE, vol. 8, no. 10, Article ID e78430, 2013.

[15] C. Kahveci, M. Koldemir, P. Cagatay et al., "Relationship of transcription factor 7 like 2 gene rs7903146 variation with type 2 diabetes and obesity related parameters," Diabetes \& Metabolic Syndrome, vol. 6, no. 1, pp. 48-53, 2012.

[16] D. Bodhini, V. Radha, M. Dhar, N. Narayani, and V. Mohan, "The rs12255372(G/T) and rs7903146(C/T) polymorphisms of the TCF7L2 gene are associated with type 2 diabetes mellitus in Asian Indians," Metabolism: Clinical and Experimental, vol. 56, no. 9, pp. 1174-1178, 2007.

[17] G. F. Marquezine, A. C. Pereira, A. G. P. Sousa, J. G. Mill, W. A. Hueb, and J. E. Krieger, "TCF7L2 variant genotypes and type 2 diabetes risk in Brazil: significant association, but not a significant tool for risk stratification in the general population," BMC Medical Genetics, vol. 9, article 106, 2008.

[18] G. Musso, R. Gambino, G. Pacini, G. Pagano, M. Durazzo, and M. Cassader, "Transcription factor 7-like 2 polymorphism modulates glucose and lipid homeostasis, adipokine profile, and hepatocyte apoptosis in NASH," Hepatology, vol. 49, no. 2, pp. 426-435, 2009.

[19] H. J. Choi, D.-H. Lee, H. J. Jeon, D. S. Kim, Y. H. Lee, and T. Oh, "Transcription factor 7-like 2 (TCF7L2) gene polymorphism rs7903146 is associated with stroke in type 2 diabetes patients with long disease duration," Diabetes Research and Clinical Practice, vol. 103, no. 3, pp. e3-e6, 2014.

[20] J. Wang, L. Li, J. Zhang et al., "Association of rs7903146 (IVS3C/T) and rs290487 (IVS3C/T) polymorphisms in TCF7L2 with type 2 diabetes in 9,619 Han Chinese population," PLoS ONE, vol. 8, no. 3, Article ID e59053, 2013.
[21] J. Delgado-Lista, P. Perez-Martinez, A. García-Rios et al., "Pleiotropic effects of TCF7L2 gene variants and its modulation in the metabolic syndrome: from the LIPGENE study," Atherosclerosis, vol. 214, no. 1, pp. 110-116, 2011.

[22] R. B. Ramos, D. Wiltgen, and P. M. Spritzer, "Polymorphisms of TCF7L2 gene in South Brazilian women with polycystic ovary syndrome: a Cross-sectional study," European Journal of Endocrinology, vol. 169, no. 5, pp. 569-576, 2013.

[23] R. Gambino, S. Bo, L. Gentile et al., “Transcription factor 7-like 2 (TCF7L2) polymorphism and hyperglycemia in an adult italian population-based cohort," Diabetes Care, vol. 33, no. 6, pp. 1233$1235,2010$.

[24] S. Cauchi, D. Meyre, H. Choquet et al., "TCF7L2 rs7903146 variant does not associate with smallness for gestational age in the French population," BMC Medical Genetics, vol. 8, article 37, 2007.

[25] S. Cauchi, D. Meyre, H. Choquet et al., "TCF7L2 variation predicts hyperglycemia incidence in a French general population: the data from an epidemiological study on the Insulin Resistance Syndrome (DESIR) study," Diabetes, vol. 55, no. 11, pp. 3189-3192, 2006.

[26] S. E. Humphries, D. Gable, J. A. Cooper et al., "Common variants in the TCF7L2 gene and predisposition to type 2 diabetes in UK European Whites, Indian Asians and AfroCaribbean men and women," Journal of Molecular Medicine, vol. 84, no. 12, pp. 1005-1014, 2006.

[27] S. Bo, R. Gambino, G. Ciccone et al., "Effects of TCF7L2 polymorphisms on glucose values after a lifestyle intervention," The American Journal of Clinical Nutrition, vol. 90, no. 6, pp. 1502-1508, 2009.

[28] S. Ereqat, A. Nasereddin, S. Cauchi, K. Azmi, Z. Abdeen, and R. Amin, "Association of a common variant in TCF7L2 gene with type 2 diabetes mellitus in the Palestinian population," Acta Diabetologica, vol. 47, supplement 1, pp. S195-S198, 2010.

[29] Y. Yan, K. E. North, C. M. Ballantyne et al., “Transcription factor 7-like 2 (TCF7L2) polymorphism and context-specific risk of type 2 diabetes in African American and caucasian adults: the atherosclerosis risk in communities study," Diabetes, vol. 58, no. 1, pp. 285-289, 2009.

[30] Y. Yan, R. Klein, G. Heiss et al., "The transcription factor 7-like 2 (TCF7L2) polymorphism may be associated with focal arteriolar narrowing in Caucasians with hypertension or without diabetes: the ARIC Study," BMC Endocrine Disorders, vol. 10, article 9, 2010.

[31] Z. Schroner, M. Javorsky, R. Tkacova et al., "Effect of sulphonylurea treatment on glycaemic control is related to TCF7L2 genotype in patients with type 2 diabetes, Diabetes, Obesity \& Metabolism, vol. 13, no. 1, pp. 89-91, 2011.

[32] N. J. Welton, D. M. Caldwell, E. Adamopoulos, and K. Vedhara, "Mixed treatment comparison meta-analysis of complex interventions: psychological interventions in coronary heart disease," American Journal of Epidemiology, vol. 169, no. 9, pp. 1158-1165, 2009.

[33] Y.-C. Chang, Y.-F. Chiu, L. L.-T. Ho et al., “TCF7L2 genetic variants and progression to diabetes in the Chinese population: pleiotropic effects on insulin secretion and insulin resistance," Journal of Molecular Medicine, vol. 88, no. 2, pp. 183-192, 2010.

[34] A. Huertas-Vazquez, C. Plaisier, D. Weissglas-Volkov et al., "TCF7L2 is associated with high serum triacylglycerol and differentially expressed in adipose tissue in families with familial combined hyperlipidaemia," Diabetologia, vol. 51, no. 1, pp. 6269, 2008. 
[35] D. K. Sanghera, S. K. Nath, L. Ortega et al., “TCF7L2 polymorphisms are associated with type 2 diabetes in Khatri Sikhs from North India: genetic variation affects lipid levels," Annals of Human Genetics, vol. 72, no. 4, pp. 499-509, 2008.

[36] C. L. Roth, A. Hinney, T. Reinehr et al., “TCF7L2 polymorphism rs7903146 and predisposition for type 2 diabetes mellitus in obese children," Hormone and Metabolic Research, vol. 40, no. 10, pp. 713-717, 2008.

[37] Y. Yan, K. E. North, G. Heiss et al., "Transcription factor 7like 2 (TCF7L2) polymorphism and context-specific risk of impaired fasting glucose in African American and Caucasian adults: the atherosclerosis risk in communities (ARIC) study," Diabetes/Metabolism Research and Reviews, vol. 26, no. 5, pp. 371-377, 2010.

[38] V. Lyssenko, R. Lupi, P. Marchetti et al., "Mechanisms by which common variants in the TCF7L2 gene increase risk of type 2 diabetes," The Journal of Clinical Investigation, vol. 117, no. 8, pp. 2155-2163, 2007.

[39] D. Savic, H. Ye, I. Aneas, S.-Y. Park, G. I. Bell, and M. A. Nobrega, "Alterations in TCF7L2 expression define its role as a key regulator of glucose metabolism," Genome Research, vol. 21, no. 9, pp. 1417-1425, 2011.

[40] D. T. Villareal, H. Robertson, G. I. Bell et al., “TCF7L2 variant rs7903146 affects the risk of type 2 diabetes by modulating incretin action," Diabetes, vol. 59, no. 2, pp. 479-485, 2010.

[41] S. F. Boj, J. H. van Es, M. Huch et al., "Diabetes risk gene and wnt effector Tcf712/TCF4 controls hepatic response to perinatal and adult metabolic demand," Cell, vol. 151, no. 7, pp. 1595-1607, 2012.

[42] G. Bardini, C. M. Rotella, and S. Giannini, "Dyslipidemia and diabetes: reciprocal impact of impaired lipid metabolism and Beta-cell dysfunction on micro- and macrovascular complications," The Review of Diabetic Studies, vol. 9, no. 2-3, pp. 82-93, 2012.

[43] G.-W. Go, R. Srivastava, A. Hernandez-Ono et al., "The combined hyperlipidemia caused by impaired Wnt-LRP6 signaling is reversed by Wnt3a rescue," Cell Metabolism, vol. 19, no. 2, pp. 209-220, 2014. 


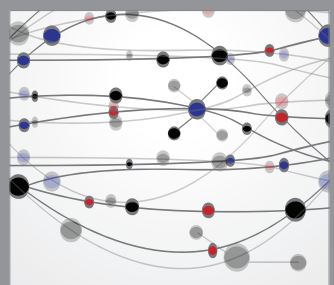

The Scientific World Journal
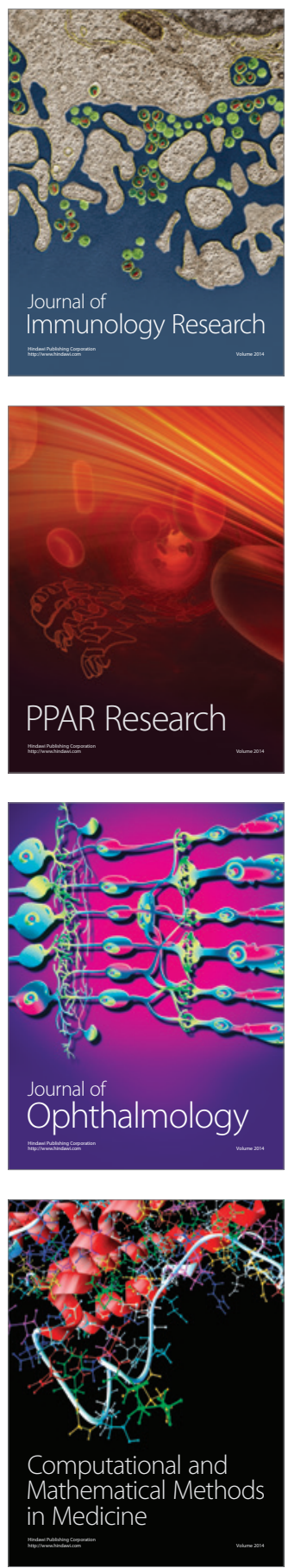

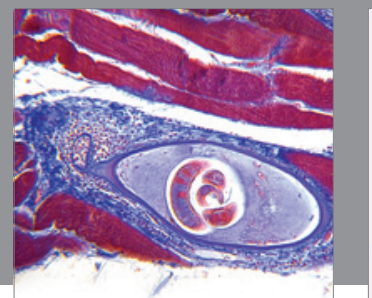

Gastroenterology

Research and Practice
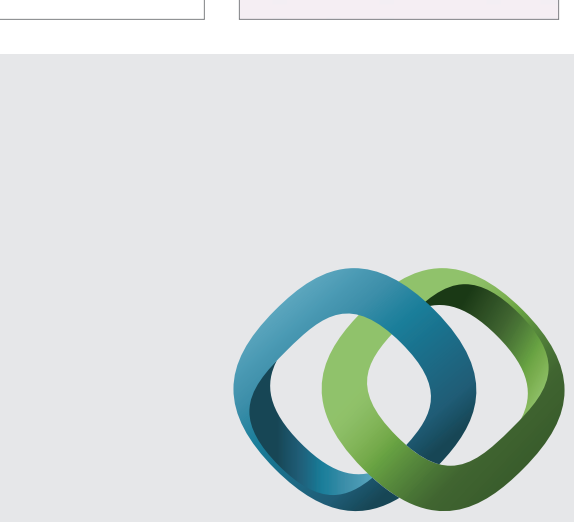

\section{Hindawi}

Submit your manuscripts at

http://www.hindawi.com
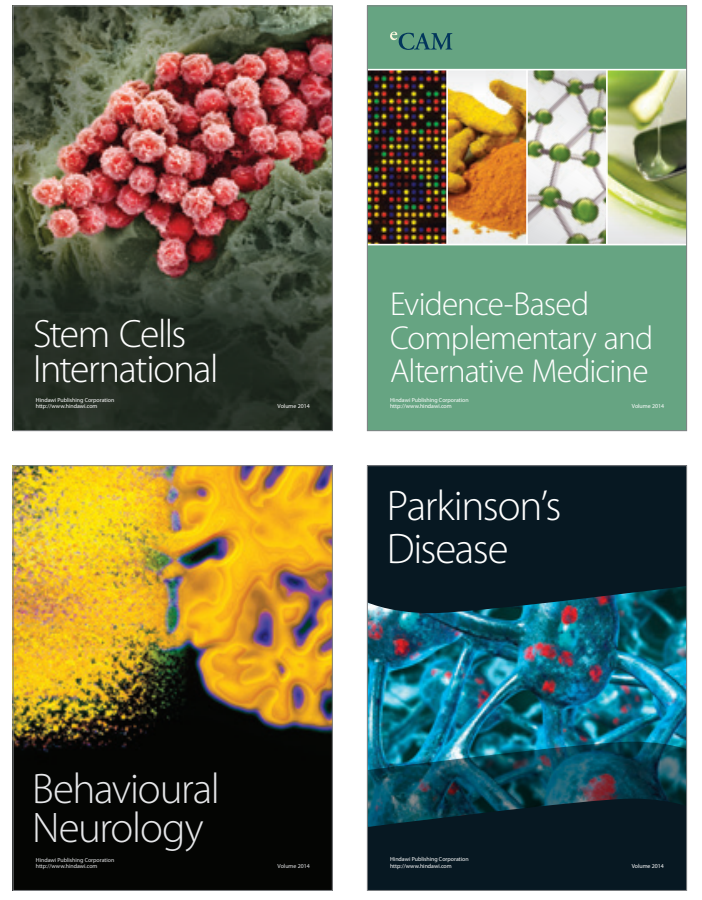
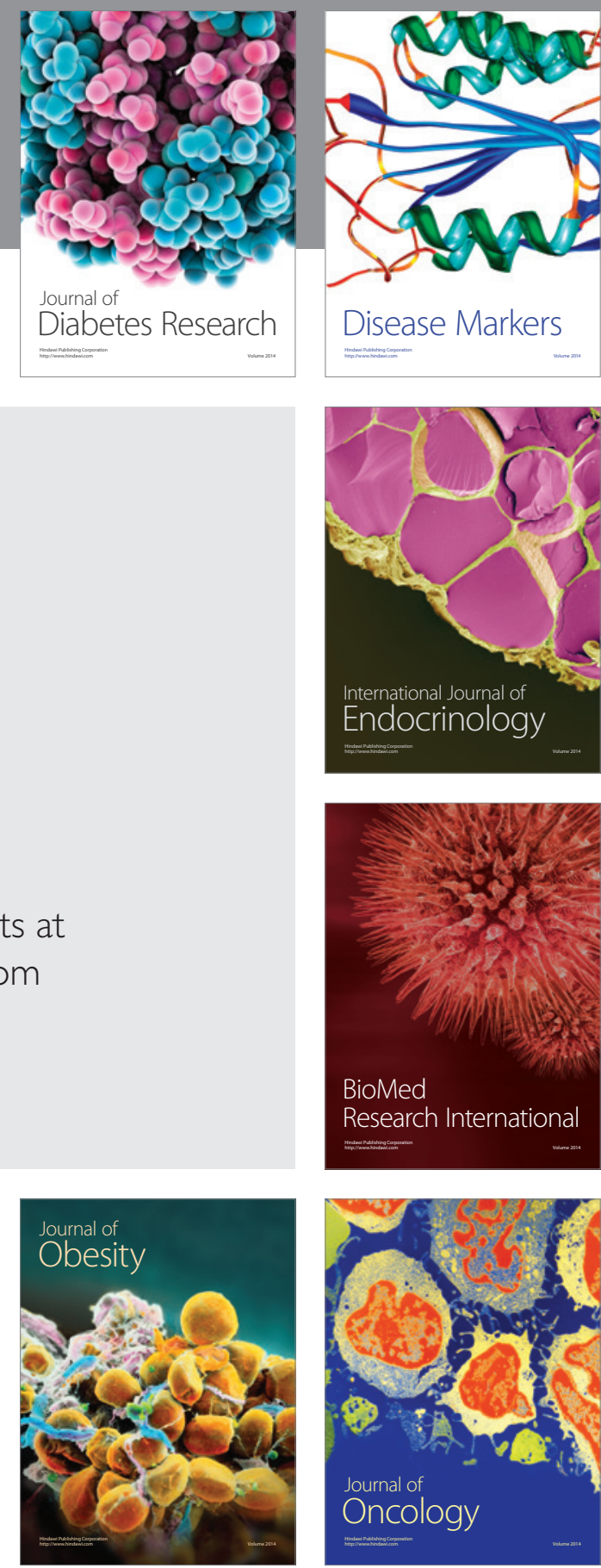

Disease Markers
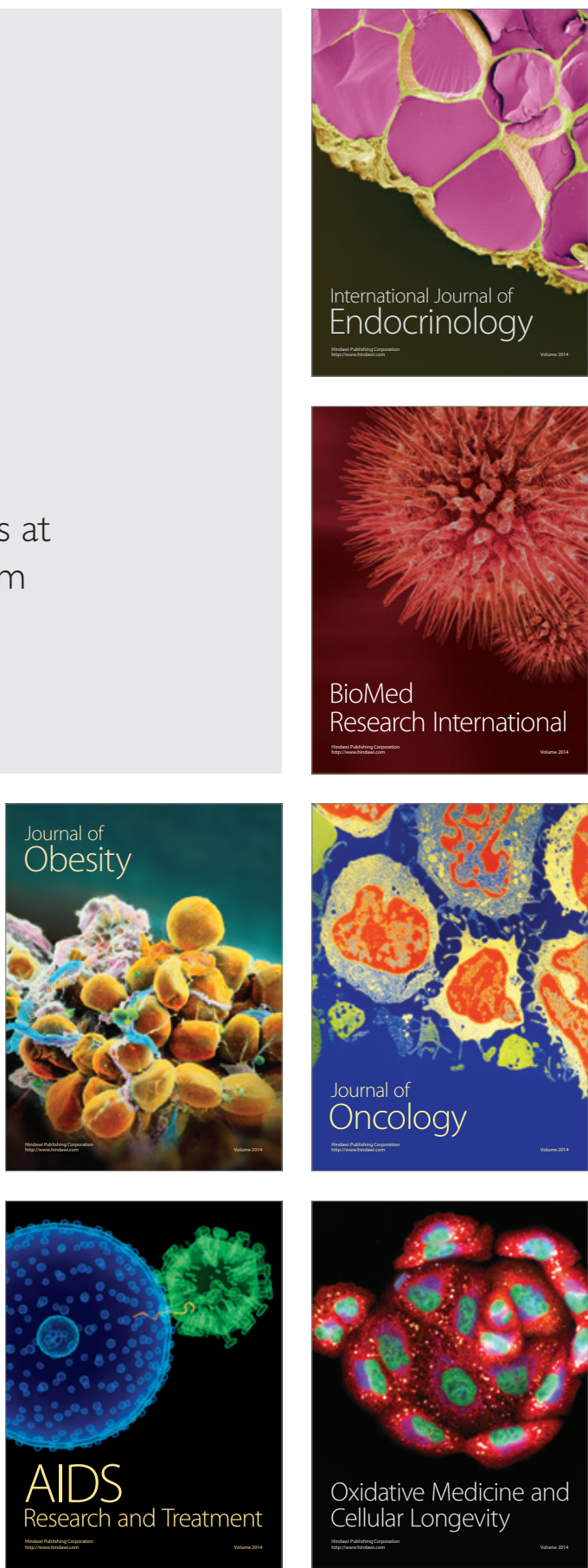